\title{
Identifying Races of Fusarium oxysporum f. sp. niveum in South Carolina Recovered From Watermelon Seedlings, Plants, and Field Soil
}

\author{
Anthony P. Keinath, ${ }^{1, \dagger}$ Virginia B. DuBose, ${ }^{1}$ Melanie M. Katawczik, ${ }^{2}$ and W. Patrick Wechter ${ }^{2}$ \\ ${ }^{1}$ Department of Plant and Environmental Sciences, Clemson University, Coastal Research and Education Center, Charleston, SC \\ 29414 \\ ${ }^{2}$ U.S. Department of Agriculture, Agricultural Research Service, U.S. Vegetable Laboratory, Charleston, SC 29414
}

\begin{abstract}
Fusarium wilt of watermelon (Citrullus lanatus), caused by the soilborne fungus Fusarium oxysporum f. sp. niveum, is the most serious disease of watermelon in South Carolina and other southeastern U.S. states. Isolates of $F$. oxysporum collected from field-grown plants, greenhouse-grown seedlings, and field soil between 1999 and 2018 were inoculated onto three differential watermelon cultivars to identify races. Of 197 isolates obtained from plants, $12 \%$ were nonpathogenic, $2 \%$ were race $0,23 \%$ were race 1 , and $63 \%$ were race 2 . One collection of isolates from greenhouse seedlings was exclusively race 1 and the other was exclusively race 2 . Seventeen of

cultigens with resistance to race 2 , did not differ significantly among five highly virulent race 2 isolates and a standard race 2 isolate, indicating a lack of a race 3 phenotype. Forma specialis-specific primers matched phenotypic race identification for $74 \%$ of the isolates. Race-specific primers based on a secreted-in-xylem elicitor present in race 0 and 1 isolates matched phenotypic race identification for $66 \%$ of the isolates. Because a majority of the $F$. oxysporum $\mathrm{f}$. sp. niveum isolates from South Carolina were race 2 , integrated management practices should be used until commercial cultivars with resistance to race 2 are available.
\end{abstract} 81 soil isolates were pathogenic: five were race 1 and 12 were race 2 . Reactions of $C$. amarus PI 296341-FR, Carolina Strongback, and SP-6,
Keywords: fungi, vegetables, etiology
Fusarium wilt of watermelon (Citrullus lanatus var. lanatus (Thunb.) Matsum. \& Nakai), caused by Fusarium oxysporum Schltdl.:Fr. f. sp. niveum (FON), is one of the most serious diseases of watermelon worldwide (Martyn 2014, 2017). Fusarium wilt can significantly reduce the number of watermelon fruit per hectare, the total weight of fruit harvested per hectare, and the size of individual fruit (Everts and Hochmuth 2011; Keinath and Hassell 2014b; Keinath et al. 2019). A large percentage of fruit may not reach the minimum marketable weight, $4.5 \mathrm{~kg}$ for triploid fruit and $6.2 \mathrm{~kg}$ for diploid fruit. For example, only $12 \%$ of the fruit produced by a susceptible triploid cultivar were marketable size in heavily infested fields in Georgia and South Carolina (Keinath et al. 2019).

As in other Fusarium wilt pathosystems, races of FON are defined based on symptoms caused on differential cultivars that possess a gene or genes conferring resistance to different races. Based on the current set of four differential Citrullus cultivars for Fusarium wilt of watermelon, four races of FON, designated $0,1,2$, and 3, can be distinguished (Martyn 2017). The differential cultivars Sugar Baby, Charleston Gray, and Calhoun Gray are inoculated if races 0,1 , and 2 are suspected among a collection of isolates (Zhou and Everts 2003). If race 3 isolates are suspected, then C. amarus Schrad. (syn. C. lanatus var. citroides) plant introduction (PI) 296341-FR, a Fusarium wilt-resistant selection of PI 296341 with resistance to race 2, is included (Bruton et al. 2010; Martyn 2017; Zhou et al. 2010). One problem with using the differential cultivar set is that seed of Calhoun Gray and PI 296341-FR is not available commercially. Zhou and Everts (2003) considered Calhoun Gray, followed by

${ }^{\dagger}$ Corresponding author: A. P. Keinath; tknth@clemson.edu

Funding: This material is based upon work supported by National Institute of Food and Agriculture, U.S. Department of Agriculture under award number 2014-51181-22471 and project number SC-1700536. Technical Contribution No. 6806 of the Clemson University Experiment Station.

The author(s) declare no conflict of interest.

Accepted for publication 11 March 2020.

(C) 2020 The American Phytopathological Society
Dixielee and Allsweet, to be the most effective cultivars for separating races 1 and 2 .

Races 0,1 , and 2 are distributed worldwide, whereas race 3 has a much more limited geographical range (Martyn 2014, 2017). Race 3, originally identified in Maryland, was reported recently from Florida and Georgia (Amaradasa et al. 2018; Petkar et al. 2019; Zhou et al. 2010). Currently, race 2 is the most important race within the United States and other watermelon-producing countries because it is widely distributed, and no watermelon cultivars have resistance to race 2 (Martyn 2017). Although quantitative trait loci (QTL) that contain genes conferring resistance to race 2 have been identified in citron (C. amarus), watermelon cultivars that possess this resistance are not yet available (Branham et al. 2017; Wechter et al. 2012). Race 2 is present in South Carolina, based on identification of a limited number of isolates recovered from wilted watermelon plants from commercial farms submitted for diagnosis. Of 16 isolates, 15 and one were race 2 and race 1, respectively (Keinath and DuBose 2009).

Lack of reproducibility among repeated race tests has been observed, as discussed by Bruton et al. (2010). To address this variation, Zhou and Everts (2003) calculated mean wilt incidence across all cultivars tested, rather than relying on wilt incidence of a single cultivar to distinguish race 0 from race 1 and race 1 from race 2. Isolates with a mean wilt incidence $<33 \%$ were designated as race 0 , a mean wilt incidence 33 to $66 \%$ as race 1 , and a mean wilt incidence $>66 \%$ as race 2 . In general, race 1 isolates caused $\leq 50 \%$ wilt incidence on Calhoun Gray, Dixielee, and Allsweet, whereas race 2 isolates caused wilt incidence $>50 \%$ on these three cultivars, based on previous work by Hopkins et al. (1992). Isolates were considered nonpathogenic if they caused $<15 \%$ wilt incidence on Sugar Baby, a cultivar susceptible to all races.

Because of the time required to identify races with pathogenicity tests, molecular methods have been suggested as a quicker alternative. Lin et al. (2010) designed primers based on a randomly amplified DNA fragment. Their Fon-1/Fon-2 primer set amplified a 174-base pair (bp) fragment from $13 \mathrm{FON}$ isolates, including one isolate from South Carolina, but did not amplify DNA extracted from 12 other F. oxysporum formae speciales or five other Fusarium spp. Petkar et al. (2019) used these primers to identify FON isolates before conducting pathogenicity tests on their collection of isolates. FON race 0 and race 1 isolates recently were reported to possess copies 
of secreted-in-xylem (SIX) elicitor number 6, but this protein was absent in race 2 isolates (Niu et al. 2016). The FonSIX6 primers may be useful to identify races or to separate race 2 isolates from isolates of races 0 and 1 . Niu et al. (2016) tested only seven isolates with their primers, so many more isolates need to be tested before the utility of these primers can be assessed.

Knowing which race is present in a field or on a farm allows growers to choose cultivars with partial resistance to Fusarium wilt. Diploid and triploid watermelon cultivars with resistance to races 0 and 1 are available commercially and used widely in the southern United States (Kemble et al. 2020). Triploid cultivars with resistance to race 1 also reduce the incidence of Fusarium wilt in fields with mixed populations of race 1 and race 2 (Keinath et al. 2010, 2019).

The objectives of this study were to i) determine the distribution and frequency of $F$. oxysporum $\mathrm{f}$. sp. niveum races, particularly race 2 , in the major watermelon-growing areas of South Carolina; ii) compare rating criteria for symptoms on cultigens with resistance to race 2; and iii) evaluate the specificity of two previously published primer sets on the collection of isolates from South Carolina (Lin et al. 2010; Niu et al. 2016).

\section{Materials and Methods}

Sources of FON isolates. Research field. In 2005, Fusarium wilt symptoms appeared in a research field at the Coastal Research and Education Center (CREC) in Charleston, SC (Keinath et al. 2006). Symptoms had not appeared on previous watermelon crops in this field. Symptomatic plants were collected for isolation of Fusarium spp.
Plants for diagnosis-Fields. Six samples obtained between 1999 and 2010 originated from wilted plants sent to CREC for diagnosis or confirmation of Fusarium wilt occurring in commercial fields of watermelon. Clemson University Cooperative Extension agents or growers selected these plants. The sample collected in Bamberg County in 2010 came from a spot in a field with a high incidence of symptomatic plants. One sample (Colleton County, 2008) originated from wilted plants selected by the first author on a visit to an affected field to confirm Fusarium wilt after a report of a disease outbreak.

Plants for diagnosis-Greenhouses. Outbreaks of Fusarium wilt on greenhouse-grown watermelon occurred in 2006 and 2018 in the same greenhouse in South Carolina. In 2006, pollenizer watermelon C. amarus cv. SP-1 was symptomatic. In 2018, four triploid watermelon cultivars, Fascination, Captivation, Road Trip, and Sweet Gem and pollenizer watermelon $C$. amarus cv. SP-6 were affected. In both cases, cotyledons of diseased seedlings were necrotic, while hypocotyls remained green. On most plants, the first true leaf had not yet emerged.

Commercial fields sampled. In 2008, diseased plants were collected from research plots in a 0.6-ha portion of a field in Hampton County that was part of an on-farm experiment (Keinath and Hassell 2009).

Between 2011 and 2013, six commercial watermelon fields were sampled to collect plants with symptoms of Fusarium wilt (Table 1). Collectors walked a diagonal path from corner to corner across each field. At approximately $3 \mathrm{~m}$ intervals, if any plants showed wilting of lower leaves, one plant was dug, placed in a plastic

Table 1. Distribution of races of Fusarium oxysporum f. sp. niveum on watermelon and pollenizer watermelon grown in research fields, commercial fields, and greenhouses in South Carolina and the percentage of isolates within each collection that matched the expected reaction with two PCR primer sets for the pathogen

\begin{tabular}{|c|c|c|c|c|c|c|c|c|c|c|c|c|c|c|c|c|c|}
\hline \multirow[b]{3}{*}{ County } & \multirow[b]{3}{*}{ Year } & \multirow[b]{3}{*}{ Grower } & \multirow[b]{3}{*}{ Cultivar(s) } & \multirow[b]{3}{*}{ Resistance } & \multicolumn{12}{|c|}{ Correctly identified (\%) } & \multirow[b]{3}{*}{ Total } \\
\hline & & & & & \multicolumn{3}{|c|}{ NPr } & \multicolumn{3}{|c|}{ Race 0} & \multicolumn{3}{|c|}{ Race 1} & \multicolumn{3}{|c|}{ Race 2} & \\
\hline & & & & & $\mathbf{N}^{\mathbf{s}}$ & Fon $^{t}$ & SIX $^{\mathbf{u}}$ & $\mathbf{N}$ & Fon & SIX & $\mathbf{N}$ & Fon & SIX & $\mathbf{N}$ & Fon & SIX & \\
\hline Colleton & 1999 & $1^{\mathrm{v}}$ & Stars \& Stripes & Susceptible & 0 & $\mathrm{na}^{\mathrm{w}}$ & na & 0 & na & na & 0 & na & na & 2 & $\mathrm{nd}^{\mathrm{x}}$ & nd & 2 \\
\hline Charleston & 2005 & $\mathrm{RF}^{\mathrm{y}}$ & Various triploid & Susceptible & 2 & 100 & nd & 0 & na & na & 13 & 100 & 8 & 22 & 100 & 100 & 37 \\
\hline Colleton & 2005 & $1^{\mathrm{v}}$ & StarGazer, Sugar Heart & Resistant, susceptible & 0 & na & na & 0 & na & na & 0 & na & na & 2 & 100 & 0 & 2 \\
\hline Colleton & 2005 & $1^{\mathrm{v}}$ & StarGazer & Resistant & 0 & na & na & 0 & na & na & 0 & na & na & 1 & 0 & 100 & 1 \\
\hline Colleton & 2005 & $1^{\mathrm{v}}$ & Sugar Heart & Susceptible & 0 & na & na & 0 & na & na & 1 & 100 & 0 & 3 & 100 & 0 & 4 \\
\hline Barnwell & 2006 & $\mathrm{GH}^{\mathrm{z}}$ & SP-1 & Susceptible & 0 & na & na & 0 & na & na & 11 & 100 & 100 & 0 & na & na & 11 \\
\hline Bamberg & 2008 & Unknown $^{v}$ & Top Gun & Resistant & 0 & na & na & 0 & na & na & 0 & na & na & 2 & 100 & 0 & 2 \\
\hline Colleton & 2008 & $7^{\mathrm{v}}$ & Tri-X 313, Palomar & Susceptible & 0 & na & na & 0 & na & na & 0 & na & na & 5 & 100 & 20 & 5 \\
\hline Hampton & 2008 & 2 & SS7187 & Susceptible & 2 & 100 & nd & 0 & na & na & 0 & na & na & 17 & 7 & 100 & 19 \\
\hline Bamberg & 2010 & $3^{v}$ & Palomar & Susceptible & 1 & 100 & 100 & 1 & 0 & 0 & 1 & 100 & 100 & 9 & 100 & 0 & 12 \\
\hline Barnwell & 2011 & 4 & Revolution & Resistant & 9 & 89 & nd & 0 & na & na & 0 & na & na & 0 & na & na & 9 \\
\hline Barnwell & 2011 & 5 & Revolution & Resistant & 5 & 100 & 100 & 1 & 0 & 0 & 1 & 100 & 0 & 2 & 0 & 100 & 9 \\
\hline Colleton & 2011 & 1 & Liberty, Wrigley & Susceptible & 1 & 100 & 100 & 0 & na & na & 3 & 67 & 67 & 15 & 80 & 33 & 19 \\
\hline Hampton & 2012 & 2 & Yellow Buttercup & Susceptible & 0 & na & na & 1 & 100 & 100 & 2 & 100 & 100 & 7 & 57 & 50 & 10 \\
\hline Barnwell & 2013 & 6 & Bold Ruler & Susceptible & 2 & 100 & nd & 0 & na & na & 12 & 100 & 67 & 10 & 100 & 100 & 24 \\
\hline Barnwell & 2013 & 5 & Revolution & Resistant & 1 & 100 & 100 & 0 & na & na & 2 & 0 & 0 & 18 & 39 & 94 & 21 \\
\hline Barnwell & 2018 & $\mathrm{GH}^{\mathrm{z}}$ & Various triploid & Various & 0 & na & na & 0 & na & na & 0 & na & na & 10 & 0 & 100 & 10 \\
\hline \multicolumn{5}{|c|}{ Total number of isolates } & 23 & na & na & 3 & na & na & 46 & na & na & 125 & na & na & 197 \\
\hline \multicolumn{5}{|c|}{ Percentage of all isolates } & 12 & na & na & 2 & na & na & 23 & na & na & 63 & na & na & 100 \\
\hline \multicolumn{5}{|c|}{ Percentage of pathogenic isolates } & na & na & na & 2 & na & na & 26 & na & na & 72 & na & na & 100 \\
\hline \multicolumn{5}{|c|}{ Percentage of isolates correctly reacting with primers } & na & 96 & 100 & na & 33 & 33 & na & 93 & 54 & na & 63 & 72 & na \\
\hline
\end{tabular}

$\mathrm{r}$ Races were identified based on greenhouse pathogenicity tests with three differential cultivars. Nonpathogenic isolates had a mean disease incidence $\leq 15 \%$ (Zhou and Everts 2003).

s Number of isolates identified as the given race.

$t$ Percentage of pathogenic isolates yielding or percentage of nonpathogenic isolates not yielding a 174-bp DNA fragment with the Fon-1/Fon-2 forma specialisspecific primers (Lin et al. 2010). Amplification is expected with all pathogenic isolates, regardless of race, but not with nonpathogenic isolates. Amplification was performed with 192 isolates.

u Percentage of race 0 or 1 isolates or percentage of nonpathogenic or race 2 isolates not yielding a 430-bp DNA fragment with the FonSIX6 primers (Niu et al. 2016). Amplification is expected with race 0 or race 1 isolates but not with nonpathogenic or race 2 isolates. Amplification was performed with 173 isolates that included only four of the 23 nonpathogenic isolates.

v Sample submitted to first author for diagnosis.

${ }^{\mathrm{w}}$ na $=$ not applicable

${ }^{x}$ nd $=$ not done.

y $\mathrm{RF}=$ research field at the Clemson University Coastal Research and Education Center, Charleston, SC.

z $\mathrm{GH}=$ commercial greenhouse in South Carolina. 
bag, and stored in a cooler for transport to the laboratory. A maximum of 30 plants were collected per field.

Soil isolates. Soil samples were collected with a soil probe to $30 \mathrm{~cm}$ depth next to symptomatic plants on a commercial watermelon farm in Hampton County in 2008 (Keinath and Hassell 2009).

Recovery of FON isolates from plants and soil. Komada's medium, which is semiselective for $F$. oxysporum, was used for all isolations (Komada 1975). Small pieces (ca. $3 \times 3 \mathrm{~mm}$ ) that included discolored vascular tissue were cut from the base of the main stem or vine. Tissue pieces were surface disinfested in $0.5 \%$ sodium hypochlorite for $1 \mathrm{~min}$, rinsed in sterile deionized water, and placed onto Komada's medium. Plates were held under cool-white fluorescent lights at 22 to $24^{\circ} \mathrm{C}$ for 5 to 7 days. Isolates resembling $F$. oxysporum with white to pale orange, fluffy aerial mycelium and tan to purplebrown colony reverse color were selected (Komada 1975). Soil (10 g) was suspended in $90 \mathrm{ml}$ water, and dilutions were spread onto plates of Komada's medium. Isolates resembling $F$. oxysporum were selected from dilution plates as described above. All isolates were subcultured by spreading a microconidial suspension on water agar and selecting a single germinated conidium. Isolates were stored on dried filter paper at $4^{\circ} \mathrm{C}$.

Pathogenicity tests. Pathogenicity tests to identify races were done in 1999 and between 2005 and 2018. Suspensions of microconidia for each $F$. oxysporum isolate were prepared in potato dextrose broth as described previously (Keinath and Hassell 2014a). Black Diamond was used as the cultivar susceptible to all races in tests done prior to 2008, and Sugar Baby was used in all subsequent tests. Charleston Gray was used as the cultivar with resistance to race 0 in most tests, except that Crimson Sweet was used in tests done in 2008 and 2009. Allsweet was used as the cultivar with resistance to races 0 and 1 in all tests. Watermelon was seeded in Fafard 3B potting mix (Sun Gro Horticulture, Agawam, MA) in 128-cell flats and grown in a greenhouse for ca. 14 days. Seedlings were inoculated when the first true leaf was fully expanded. Seedlings were removed from cells, and the roots were rinsed gently to remove adhering potting soil. Roots were dipped for $10 \mathrm{~s}$ in a suspension of $10^{6}$ microconidia/ml and transplanted into $10-\mathrm{cm}$ plastic pots filled with Fafard 3B potting mix. For each cultivar-isolate combination, 20 plants were inoculated, and four plants were placed in each of five replicate pots. Twenty plants of each differential cultivar were dipped in water and planted as described to serve as the noninoculated control treatment. Two and three weeks after inoculation, the number of plants with no symptoms, wilt symptoms, and the number of dead plants were recorded. Mean percentage of wilted and dead plants was calculated for each cultivar and across all three cultivars (Zhou and Everts 2003). One or two isolates previously characterized as race 2 in 1999 (isolates 997 and 998) were included in the six tests done in 2005 and 2006. Two standard isolates previously characterized as race 1 (isolate B05-07) and race 2 (B05-30C1) were included in the remaining tests done starting in December 2006 (Keinath and Hassell 2014a; Wechter et al. 2012). A total of 50 tests were done with a median of 10 isolates per test (range 6 to 17). All isolates were tested twice, and a few isolates were tested three times (Zhou and Everts 2003). The greenhouse temperature was set at $24 / 21^{\circ} \mathrm{C}$ day/ night, and supplemental lighting was not used. In tests done between 2005 and 2011, F. oxysporum was reisolated on Komada's medium from two living Allsweet plants from each of two pots (replications) inoculated with each isolate to confirm its presence in diseased plants (Keinath and Hassell 2014a; Komada 1975).

Soil isolates of FON collected from a commercial farm in 2008 were tested in a quick pathogenicity test on Sugar Baby seeds. Procedures were followed as described by Zhou and Everts (2003) except that two replications were used per test, and the tests were repeated. Race 1 isolate $\mathrm{B} 05-07$, race 2 isolate $\mathrm{B} 05-30 \mathrm{C} 1$, and mineral salts solution were included in all tests as control treatments. Isolates that caused $>15 \%$ mean disease incidence were inoculated onto Sugar Baby seedlings with the root-dip method described above. Race 1 isolate B05-07 and water were included as control treatments. Isolates that caused $>15 \%$ disease on Sugar Baby seedlings were inoculated onto Sugar Baby, Charleston Gray, and Allsweet as described above to determine race phenotype. Race tests were done twice. Race 1 isolate B05-07, race 2 isolate A08-44, and water were included in all tests as control treatments. F. oxysporum was reisolated from two Allsweet plants from each of two pots (replications) inoculated with each isolate to confirm its presence in diseased plants (Keinath and Hassell 2014a).

After pathogenicity tests were completed, five highly virulent race 2 isolates from South Carolina commercial fields were tested in an additional experiment on another set of cultivars to determine if any of them could be race 3 (Zhou et al. 2010). Each isolate selected caused a mean of $>90 \%$ wilt incidence in the previous race tests. The experiment was done three times on 16 March 2018, 20 November 2018 , and 23 January 2019, and each repetition is referred to as a trial. Three cultivars of $C$. amarus were used: 296341-FR (provided by W. P. Wechter, USDA), Carolina Strongback (provided by W. P. Wechter, USDA), and SP-6 (Syngenta Seeds, Woodland, CA). Seed of 296341-FR was limited, so it could only be included in trial one; SP-6 was substituted in trials two and three. All $C$. amarus cultivars are resistant to FON races 0, 1, and 2. C. lanatus Allsweet, resistant to FON races 0 and 1, served as a race 2-susceptible control treatment in all trials (Wechter et al. 2016; Zhou and Everts 2003). Two standard isolates previously characterized as race 1 (B05-07) and race 2 (B05$30 \mathrm{C} 1$ ) were included in each trial.

Seedlings, 12 to 20 per cultivar per test, were inoculated by dipping roots in microconidial suspensions or water as described above. Two and three weeks after inoculation, the number of symptomatic plants was recorded as described above. An additional category of plants with chlorotic or necrotic cotyledons and first or first and second true leaves was added to the ratings to account for symptoms that appeared on 296341-FR, Carolina Strongback, or SP-6 with some isolates. Pieces from the lower stem of selected cultigens were cultured as described above to isolate $F$. oxysporum. In trial one, plants of PI 296341-FR and Carolina Strongback from all four replications were cultured, along with Allsweet inoculated with race 1 . In trial three, plants of SP-6 from two replications were cultured.

Data were analyzed with SAS PROC GLIMMIX (SAS, Inc., Cary, NC). Counts of diseased and dead plants were summed from all replicate pots within a trial and used to calculate wilt incidence for each cultivar, which was transformed by calculating the arcsine of the square root before analysis. Cultivar, isolate, and trial were considered fixed effects, and replication was considered a random effect. Cultivar-isolate means were compared with Fisher's protected least-significant difference test evaluated at $P=0.05$.

Reactions with FON primers. Fusarium cultures stored on dried filter paper were removed from storage at $4{ }^{\circ} \mathrm{C}$ and grown on quarterstrength potato dextrose agar for 5 days at $22^{\circ} \mathrm{C}$. Five $0.5-\mathrm{cm}^{2} \mathrm{sec}-$ tions of each isolate were transferred into $50 \mathrm{ml}$ potato dextrose broth and shaken at $150 \mathrm{RPM}$ at $22^{\circ} \mathrm{C}$ for 7 days. The culture liquid was removed by filtering through sterile cheese cloth. Hyphae $(100 \mathrm{mg})$ were transferred to a $1.5-\mathrm{ml}$ tube. DNA was extracted using a DNeasy plant mini kit (Qiagen, Germantown, MD), and genomic DNA was quantified using a Qubit Fluorometer (ThermoFisher Scientific, Waltham, MA).

PCR amplifications were performed using a Stratagene Mx3005P (Agilent Technologies, Santa Clara, CA). Reaction mixtures consisted of $1 \mu \mathrm{l}(10 \mathrm{ng} / \mu \mathrm{l})$ of purified genomic DNA, $6.25 \mu \mathrm{l}$ of $2 \times$ master mix of Brilliant II SYBR Green QPCR Master Mix (Agilent Technologies), $0.1875 \mu$ l of a 1:500 dilution of $1 \mathrm{mM}$ reference dye, and $0.5 \mu \mathrm{l}$ of $10 \mu \mathrm{mol} /$ liter forward and reverse primers for a total reaction volume of $12.5 \mu \mathrm{l}$. Amplification conditions were $95^{\circ} \mathrm{C}$ for $10 \mathrm{~min}$ and 40 cycles of denaturation at $95^{\circ} \mathrm{C}$ for $30 \mathrm{~s}$, annealing at $55^{\circ} \mathrm{C}$ for $1 \mathrm{~min}$ and extension at $70^{\circ} \mathrm{C}$ for $1 \mathrm{~min}$, followed by $95^{\circ} \mathrm{C}$ for $1 \mathrm{~min}, 55^{\circ} \mathrm{C}$ for $30 \mathrm{~s}$, and $95^{\circ} \mathrm{C}$ for $30 \mathrm{~s}$ for a dissociation curve. Two different primer sets were used in separate reactions. The FON forma specialis-specific primers designated Fon-1/Fon-2 developed by Lin et al. (2010) were used on 190 isolates, and primers developed to detect the FonSIX6 gene by Niu et al. (2016) were used with 184 isolates (Table 1). Results were analyzed with MxPro QPCR Software version 4.10 (Agilent Technologies). A nontemplate control of water and race 2 isolate $\mathrm{B} 05-30 \mathrm{C} 1$ were used as negative and 
positive controls, respectively, in every set of reactions. When the FonSIX6 primers were used, race 1 isolate B05-07 also was used as a positive control. An initial reaction with $F$. oxysporum f. sp. melonis isolate 26406 (which originated from Illinois in 2013) was used to demonstrate no false positive reactions resulted with either primer set (data not shown). Watermelon actin primers R2 (tcacacttcatgatrgagtt) and F1 (gaaattgtccgkgacatgaa) were added to DNA of isolates that did not amplify or had high Ct values $(\mathrm{Ct}>28)$ with the Lin et al. (2010) or Niu et al. (2016) primers, and the protocol listed above was run to confirm that the DNA was amplifiable.

\section{Results}

Race identification with pathogenicity tests. Plant isolates. Twenty-three (12\%) of the $197 \mathrm{~F}$. oxysporum isolates recovered from plants were not pathogenic on watermelon, based on the criterion of mean disease incidence $\leq 15 \%$ on Sugar Baby used by Zhou and Everts (2003). All isolates also had mean incidence $\leq 15 \%$ across all three cultivars calculated for both trials. Two isolates caused no disease on any plants in either of two trials. Twelve isolates had mean disease incidence $<33 \%$ in one trial and no disease on any cultivar in the other trial. The other nine isolates classified as nonpathogenic had low disease incidence in both trials.

Pathogenic isolates accounted for $88 \%$ of the total number of plant isolates. Of the 174 pathogenic isolates, $2 \%$ (three isolates) were race $0,26 \%$ (46 isolates) were race 1 , and $72 \%$ (125 isolates) were race 2. All three isolates classified as race 0 had a mean incidence $>15 \%$ on cv. Sugar Baby but an overall mean incidence $<33 \%$ across the three differential cultivars (Zhou and Everts 2003).

All 46 isolates classified as race 1 had mean incidence $<50 \%$ on Allsweet, the differential cultivar for determining whether an isolate is race 1 or race 2 . Three race 1 isolates from commercial fields did not cause any disease on Allsweet, and two additional isolates each caused disease on only one of 40 plants. Seven of the 46 race 1 isolates had a mean incidence of 67 or $68 \%$ across all three differential cultivars, but because mean incidence on Allsweet was $\leq 40 \%$, these isolates were classified as race 1 , even though they marginally exceeded the upper threshold of $66 \%$ mean incidence used by Zhou and Everts (2003).

All 125 isolates classified as race 2 had a mean incidence $>50 \%$ on Allsweet. Ten isolates from commercial fields had a mean incidence $<66 \%$ on the three differential cultivars but were classified as race 2 based on incidence on Allsweet of $\geq 53 \%$. The oldest isolates were collected from a commercial field in 1999. Race 2 isolates were recovered from symptomatic plants more frequently than nonpathogenic, race 0 , and race 1 isolates $(t$ tests, $P=0.0005, P=0.0001$, and $P=0.0008$, respectively). Susceptibility of the cultivars from which isolates were recovered did not affect the percentage of isolates that were nonpathogenic or that were classified into the three races ( $t$ tests, $P \geq 0.06$ ). $F$. oxysporum was recovered from all inoculated Allsweet plants cultured on Komada's medium.

Field-grown plants were the source of 153 of the 174 pathogenic isolates. The distribution of races among field isolates was $2 \%$ race 0 (three isolates), $23 \%$ race 1 (35 isolates), and 75\% race 2 (115 isolates). Seven isolate collections were obtained by sampling fields systematically as described previously. Five collections consisted of a mix of nonpathogenic and pathogenic isolates, one collection included only pathogenic isolates, and one collection consisted of only nonpathogenic isolates. Two, five, and six of the six collections with pathogenic isolates included one or more isolates classified as race 0 , 1 , and 2, respectively (Table 1). Seven collections of isolates originated from plants submitted for diagnosis. Twenty-four, two, one, and one of the 28 isolates in these collections were classified as race $2,1,0$, and nonpathogenic, respectively. The proportion of isolates that were identified as race 2 was greater in the diagnosis collections $(0.93 \pm 0.04$ [standard error] $)$ than in collections obtained by sampling fields $(0.55 \pm 0.13)(P=0.029)$. Proportions of isolates identified as nonpathogenic, race 0 , and race 1 did not differ between diagnosis and systematically sampled collections $(P \geq 0.10)$. Twenty-one isolates originated from greenhouse-grown seedlings.
All 11 of the 2006 isolates were race 1 , and all 10 of the 2018 isolates were race 2 (Table 1 )

The field in Barnwell County planted in 2013 to the susceptible cultivar Bold Ruler had been planted yearly to watermelon for approximately 25 years, according to the grower. Among the 24 pathogenic isolates collected from symptomatic plants in this field, 12 were race 1 and 10 were race 2 (Table 1 ).

Soil isolates. Of the 81 soil isolates tested in the quick pathogenicity test on Sugar Baby seeds, 44 isolates caused no symptoms in either test, 22 isolates caused symptoms on $>15 \%$ of the seedlings in both tests, and 14 isolates caused symptoms on $>15 \%$ of the seedlings in only one test. One additional isolate was tested once with $100 \%$ disease incidence. Of the 53 isolates further tested on Sugar Baby seedlings with a standard root-dip inoculation, disease incidence was $\geq 50 \%$ for 17 isolates, while incidence was $\leq 10 \%$ for the remaining 36 isolates, which were considered nonpathogenic. Disease incidence in the quick pathogenicity test was correlated with disease incidence in the Sugar Baby root-dip test (Pearson correlation coefficient $0.841, P<0.0001)$. However, incidences in the two inoculation methods were not correlated when only the 17 pathogenic isolates were included (Pearson correlation coefficient 0.323, $P=$ 0.32). The 17 pathogenic soil isolates included five isolates of race $1(29 \%)$ and 12 isolates of race $2(71 \%)$.

Testing for race 3. In the experiment to detect race 3 isolates, the effects of isolate, cultivar, and the isolate-by-cultivar interaction were significant $(P \leq 0.0001)$ in all three trials. Disease incidence based on wilting and death of inoculated plants was $>65 \%$ on Allsweet, the race 2 -susceptible cultivar, with all race 2 isolates. Incidence with all race 2 isolates was significantly greater on Allsweet than on noninoculated control plants and on plants inoculated with the standard race 1 isolate $\mathrm{B} 05-07$ (Tables 2 and 3). Incidence with the race 1 isolate B05-07 was $<4 \%$ and did not differ from the noninoculated control on any cultivar in any trial. In trial one, $F$. oxysporum was recovered from $92 \%$ of inoculated PI 296341-FR plants, $96 \%$ of inoculated Carolina Strongback plants, and $83 \%$ of Allsweet plants inoculated with race 1 . In trial three, $F$. oxysporum was recovered from $57 \%$ of inoculated SP-6 plants but not from noninoculated plants. $F$. oxysporum was not recovered from plants inoculated with isolate JLP-13 or the standard race 1 isolate.

In general, disease incidence with race 2 isolates, including the standard race 2 isolate $\mathrm{B} 05-30 \mathrm{C} 1$, was significantly greater on Allsweet than on the three cultivars of $C$. amarus with resistance to race 2, except on Carolina Strongback inoculated with isolates F11-10 and JLP-13 in trial one and isolates A08-12 and NP-2 in trial two (Tables 2 and 3). In trial one, disease incidence for all isolates on PI 296341-FR was significantly lower or equally low $(\leq 6 \%)$ compared with incidence on Carolina Strongback (Table 2). In trial two, isolates A08-12, NP-20, JLP-13, and B05-30C1 had higher incidence on Carolina Strongback than on the noninoculated control, and isolates JLP-13 and BG-05 had significantly higher incidence on SP-6 than on the noninoculated control (Table 3). Isolates A0812, NP-20, and B05-30C1 had higher incidence on Carolina Strongback than they did on SP-6, but incidence did not differ between Carolina Strongback and SP-6 with the other isolates. In trial three, only isolate JLP-13 had higher incidence on Carolina Strongback than on the noninoculated control; on SP-6, no isolates differed from the noninoculated control. There were no significant differences between Carolina Strongback and SP-6 with any isolate $(P=0.05)$ (Table 3).

Mean disease incidence based on wilting and death caused by race 2 isolates was greatest on Allsweet $(94.0 \pm 3.2 \%$ [standard error]), less on Carolina Strongback (30.4 $\pm 8.4 \%)$, and least on PI 296341-FR $(4.6 \pm 3.2 \%)$ and SP-6 $(4.6 \pm 2.4 \%)$. Based on the disease incidence values used by Martyn and McLaughlin (1983) for designating cultivar resistance, Allsweet was susceptible to race 2, Carolina Strongback was moderately resistant to race 2, and PI 296341-FR and SP-6 were resistant to race 2.

In the experiment to detect race 3 isolates, some plants exhibited an additional symptom besides wilting of the entire plant or plant death. The cotyledons and the first true leaf of inoculated plants turned yellow or became necrotic by 3 weeks after inoculation. 
Yellowing or necrosis of leaves appeared on plants inoculated with all isolates but rarely on the noninoculated control plants. This symptom was more frequent on PI 296341-FR, Carolina Strongback, and SP-6 than on Allsweet (Tables 2 and 3). When plants with symptoms on the lowest leaves were included in disease incidence, mean incidence increased by $5.2 \% \pm 2.0$ (standard error) $(P<0.02)$ on Allsweet, $59.8 \% \pm 11.9(P=0.0041)$ on PI $296341-\mathrm{FR}, 30.8 \% \pm 3.4$ $(P \leq 0.0001)$ on Carolina Strongback, and $11.7 \% \pm 3.5(P=$ $0.006)$ on SP-6 compared with incidence based only on wilted or dead plants (Table 2,3). This increase was observed with five race 2 isolates and the standard race 1 isolate ( $t$ tests, $P \leq 0.03$ ), but the difference was slight for the standard race 2 isolate $(P=0.07)$.

In the analysis of variance for disease incidence based on wilting, death, and yellowing, there was no isolate-by-cultivar interaction $(P=0.21)$ and no effect of cultivar $(P=0.11)$ in trial one, but isolate means differed from each other $(P \leq 0.0001)$. In trials two and three, all three sources of variation were highly significant $(P \leq 0.0001)$. In all three trials, incidence based on wilting and yellowing on Allsweet was greater for all race 2 isolates than for the race 1 isolate and the noninoculated control (Tables 2 and 3). In trial one, incidence on PI 296341-FR with all race 2 isolates was $>70 \%$ and greater than the noninoculated control. In trials one and two, incidence based on wilting and yellowing was $\geq 50 \%$ on all inoculated Carolina Strongback plants than on the noninoculated control. In trial three, incidence based on wilting, death, and yellowing was greater on Carolina Strongback inoculated with race 2 isolates NP-20, JLP-13, and A08-12 and race 1 isolate $\mathrm{B} 05-07$ than on the noninoculated control. On SP-6, only a few race 2 isolates had greater incidence than the inoculated control in trials two and three (Tables 2 and 3 ).

On Carolina Strongback, incidence was greater with the race 1 isolate B05-07 than in the noninoculated control in all three trials (Tables 2 and 3). In trial one, six race 2 isolates had greater incidence than B05-07 (Table 2). In trial two, three race 2 isolates had greater incidence than B05-07, and three race 2 isolates had similar

Table 2. Incidence of Fusarium wilt on plant introduction (PI) 296341-FR and two other cultivars of Citrullus spp. inoculated with isolates of Fusarium oxysporum f. sp. niveum in the greenhouse ${ }^{u}$

\begin{tabular}{|c|c|c|c|c|c|c|c|}
\hline \multirow[b]{2}{*}{ Isolate } & \multirow[b]{2}{*}{ Race } & \multicolumn{3}{|c|}{ Plants wilted or dead (\%) } & \multicolumn{3}{|c|}{$\begin{array}{c}\text { Plants wilted, dead, or with yellowed/necrotic lower leaves } \\
(\%) \\
\end{array}$} \\
\hline & & Allsweet $^{\mathbf{v}}$ & PI 296341-FR & Carolina Strongback & Allsweet & PI 296341-FR & Carolina Strongback \\
\hline F11-10 & 2 & $100.0 \mathrm{a}^{\mathrm{w}}$ & $19.8 \mathrm{de}$ & $85.4 \mathrm{ab}$ & $100.0 \mathrm{a}$ & $90.8 \mathrm{abc}$ & $100.0 \mathrm{a}$ \\
\hline NP-20 & 2 & $97.7 \mathrm{a}$ & $0.0 \mathrm{f}$ & $2.3 \mathrm{ef}$ & $100.0 \mathrm{a}$ & $97.7 \mathrm{ab}$ & $90.8 \mathrm{ab}$ \\
\hline JLP-13 & 2 & $100.0 \mathrm{a}$ & $5.6 \mathrm{ef}$ & $66.7 \mathrm{bc}$ & $100.0 \mathrm{a}$ & $100.0 \mathrm{a}$ & $97.7 \mathrm{ab}$ \\
\hline A08-12 & 2 & $97.7 \mathrm{a}$ & $0.0 \mathrm{f}$ & 27.0 cde & $97.7 \mathrm{ab}$ & $73.0 \mathrm{bc}$ & $100.0 \mathrm{a}$ \\
\hline BG-05 & 2 & $65.5 \mathrm{bc}$ & $0.0 \mathrm{f}$ & $5.6 \mathrm{ef}$ & $86.1 \mathrm{abc}$ & $90.8 \mathrm{bc}$ & $100.0 \mathrm{a}$ \\
\hline $\mathrm{B} 05-30 \mathrm{C} 1^{\mathrm{x}}$ & 2 & $100.0 \mathrm{a}$ & $2.3 \mathrm{ef}$ & $41.5 \mathrm{~cd}$ & $100.0 \mathrm{a}$ & $1000 \mathrm{a}$ & $100.0 \mathrm{a}$ \\
\hline B05-07y & 1 & $2.3 \mathrm{ef}$ & ND & $0.0 \mathrm{f}$ & $9.2 \mathrm{~d}$ & ND & $58.5 \mathrm{c}$ \\
\hline $\mathrm{NIC}^{\mathrm{z}}$ & - & $0.0 \mathrm{f}$ & $0.0 \mathrm{f}$ & $0.0 \mathrm{f}$ & $2.3 \mathrm{~d}$ & $0.0 \mathrm{~d}$ & $2.3 \mathrm{~d}$ \\
\hline
\end{tabular}

${ }^{u}$ Least-squares mean of incidence. Incidence was determined by counting the number of wilted or dead plants and by counting the number of plants that were dead, wilted, or had yellow or necrotic lower leaves.

v Cultivar Allsweet is $C$. lanatus resistant to races 0 and 1 ; the other two cultivars are $C$. amarus resistant to races 0,1 , and 2 .

${ }^{w}$ Means by symptom type with the same letters in columns (cultivar comparisons for each isolate) or rows (isolate comparisons for each cultivar) do not differ,

Fisher's protected least-significant difference test, $P=0.05$.

x Standard race 2 isolate included as a control.

y Standard race 1 isolate included as a control.

$\mathrm{z}$ Noninoculated control treated with water instead of a microconidial suspension.

Table 3. Incidence of Fusarium wilt on three cultivars of Citrullus spp. inoculated with isolates of Fusarium oxysporum f. sp. niveum in the greenhouse ${ }^{\mathrm{u}}$

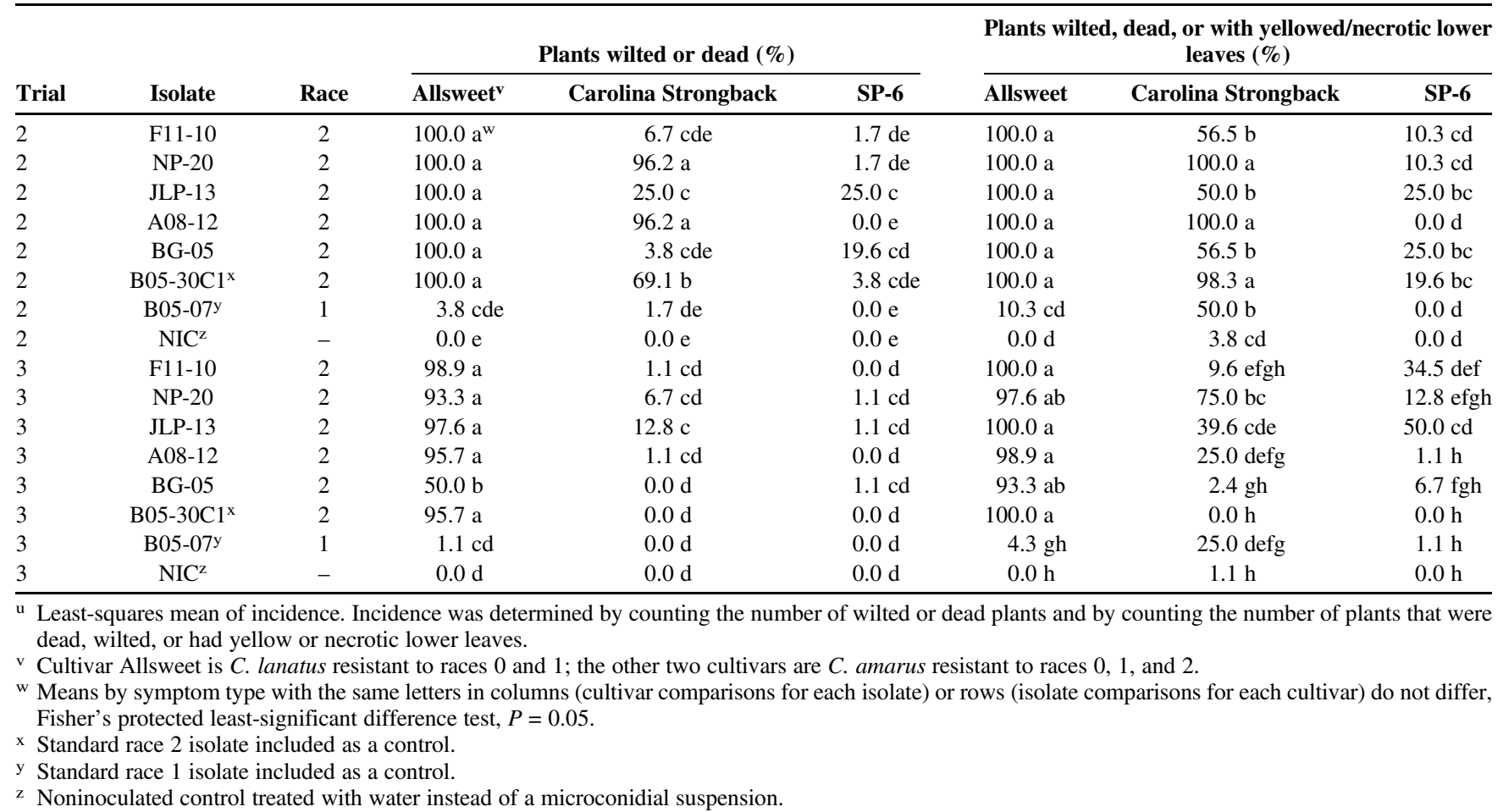


incidence. In trial three, only one race 2 isolate had greater incidence, while four race 2 isolates had similar incidence (Table 3). On SP-6, incidence with B05-07 was very low and did not differ from the noninoculated control (Table 3).

In trial one, incidence based on wilting, death, and yellowing for six race 2 isolates did not differ between Allsweet, a cultivar susceptible to race 2, and PI 296341-FR and Carolina Strongback, cultivars resistant to race 2 . In trial two, incidence based on all symptoms was greater on Allsweet than on Carolina Strongback for three race 2 isolates and did not differ for the other three race 2 isolates. In trial three, incidence did not differ between Allsweet and Carolina Strongback except for race 2 isolate NP-20. Incidence was greater on Allsweet than on SP-6 for all race 2 isolates (Table 3).

Mean disease incidence based on wilting, death, and yellowing caused by race 2 isolates was greatest on Allsweet $(98.5 \pm 0.8 \%)$ and PI 296341-FR $(92.0 \pm 4.2 \%)$, less on Carolina Strongback $(66.7 \pm 8.9 \%)$, and least on SP-6 $(16.3 \pm 4.4 \%)$. Based on the disease incidence values used by Martyn and McLaughlin (1983), Allsweet and PI 296341-FR appeared susceptible, Carolina Strongback was slightly resistant, and SP-6 was resistant to race 2.

FON primers. Fon-1/Fon-2 primers. The Fon-1/Fon-2 FON forma specialis-specific primers developed by Lin et al. (2010) were used to amplify DNA extracted from 192 isolates of $F$. oxysporum. A positive qPCR reaction, i.e., a $\mathrm{C}_{\mathrm{T}}$ value $<30$, resulted with $120(63 \%)$ of the isolates (Tables 1 and 4). The actin gene amplified in 50 DNA samples that did not yield a product with the Fon-1/Fon-2 primers, indicating the DNA was of amplifiable quality. No actin fragment was detected in two other samples, which were excluded from the datasets for both primers. The Fon-1/Fon-2 primers did not amplify DNA from 22 of the 23 nonpathogenic isolates or two of the three race 0 isolates. One nonpathogenic isolate collected from Barnwell County in 2011 and one race 0 isolate collected from Hampton County in 2012 yielded a product with these primers. Successful amplification was greater with race 1 than with race 2 isolates: $93 \%$ of race 1 isolates and $63 \%$ of race 2 isolates tested (Table 1). Twenty-six of 27 race 2 isolates from four collections did not react with the Fon1/Fon-2 primers (Table 1). A single isolate from the 15 race 2 isolates tested from the 2008 Hampton County field yielded a product. Between 50 and $96 \%$ of the pathogenic isolates in the 10 other collections reacted with the primers. Overall, reactions with the Fon-1/ Fon-2 primers matched pathogenicity identification $74 \%$ of the time.

FonSIX6 primers. Primers based on the FonSIX6 elicitor gene sequence described by Niu et al. (2016) were used to amplify DNA from 173 isolates. A positive $\mathrm{qPCR}$ reaction, i.e., a $\mathrm{C}_{\mathrm{T}}$ value $<30$, resulted with 60 isolates, and a $C_{T}$ value $>30$ or no amplification resulted with the remaining 113 isolates. The amplified fragment, however, was $430 \mathrm{bp}$ long for all isolates, not 739 bp as reported by Niu et al. (2016). A positive reaction with race 0 or race 1 isolates or no reaction with race 2 and nonpathogenic isolates was considered a match, i.e., positive identification of race. Reactions with the FonSIX6 primers matched race or pathogenicity identification $67 \%$ of the time (Table 4). Isolates belonging to race 0,1 , and 2 were identified 33,54 , and $72 \%$ of the time. There was a $100 \%$ match with nonpathogenic isolates, although only four isolates were tested.

Results with the two primer sets agreed with each other for only $41 \%$ of the isolates (Table 4). Agreement was defined as the Fon1/Fon-2 primers yielding a product for isolates identified as race 0 , 1 , or 2 and no amplification with DNA from nonpathogenic isolates, and the FonSIX6 primers yielding a product for race 0 or race 1 isolates and no amplification for all other isolates. Agreement was greatest for nonpathogenic isolates $(75 \%)$, average for race 1 isolates (54\%), and poor for race $0(33 \%)$ and race 2 isolates (35\%). Both primer sets yielded false positive results compared with the other primer set. The Fon-1/Fon-2 and FonSIX6 primers gave incorrect results for $26 \%$ and $30 \%$ of the isolates, respectively, when the other primer set matched the race identification correctly. False positive reactions with the Fon-1/Fon- 2 were greatest for race 2 isolates, while both race 1 and race 2 isolates gave false positive reactions with the FonSIX6 primers (Table 4).

\section{Discussion}

The majority $(72 \%)$ of FON isolates collected in South Carolina were race 2 . The oldest isolates were collected from a commercial field in 1999. In 2000 in Maryland and Delaware, 22, 57, and 21\% of the isolates recovered from symptomatic watermelon plants in commercial fields were race 2 , race 1 , and race 0 , respectively, while $76 \%$ of the isolates from a research field in Maryland were race 2. Zhou and Everts (2003) explained the greater proportion of race 2 isolates in the research field was due to frequent planting of race 1resistant cultivars, based on previous studies by Hopkins et al. (1992), who found that the proportion of race 1 and 2 isolates increases with cultivation of race 0 - and race 1-resistant cultivars, respectively. The selective effect of cultivar resistance on the FON population could explain the current race distribution in South Carolina, where 2,23 , and $75 \%$ of field isolates were race 0,1 , and 2 , respectively. Of six collections of field isolates obtained between 2011 and 2013, half originated from susceptible cultivars and half from cultivars resistant to races 0 and 1 , while only one-quarter of collections made prior to 2011 originated from race 1-resistant cultivars (Table 1). In contrast to results from South Carolina, Petkar et al. (2019) identified only $39 \%$ of 59 isolates from Georgia and Florida as race 2 and no isolates as race 1 . The proportion of race 0 isolates, however, was similarly low (5\%), compared with the proportion in South Carolina.

Based on development of wilt symptoms or death of inoculated plants, five highly virulent isolates of FON obtained from diseased watermelons in five commercial fields in South Carolina were race 2, not race 3 (Tables 2 and 3). Disease incidence for all isolates was $<20 \%$ on PI $296341-F R$, substantially less than incidence on this cultigen reported for race 3 isolates from Maryland (78 to 100\%) and Florida (100\%) (Amaradasa et al. 2018; Zhou and Everts 2003). In addition, incidence for the five highly virulent race 2 isolates did

Table 4. Summary of primer reactions with isolates of Fusarium oxysporum f. sp. niveum identified to race in greenhouse pathogenicity tests

\begin{tabular}{|c|c|c|c|c|c|c|c|c|c|}
\hline \multirow[b]{2}{*}{ Race $^{v}$} & \multirow[b]{2}{*}{$N^{w}$} & \multicolumn{2}{|c|}{ FonSIX6 $^{x}$ match } & \multicolumn{2}{|c|}{ FonSIX6 no match } & \multirow[b]{2}{*}{$\begin{array}{c}\% \text { agree } \\
\text { correct }\end{array}$} & \multirow[b]{2}{*}{$\begin{array}{l}\text { \% disagree } \\
\text { wrong }\end{array}$} & \multirow[b]{2}{*}{$\begin{array}{c}\% \text { false positive } \\
\text { Fon1/2 }\end{array}$} & \multirow[b]{2}{*}{$\begin{array}{c}\% \text { false positive } \\
\text { SIX6 }\end{array}$} \\
\hline & & $\begin{array}{l}\text { Fon1/2 } \\
\text { match }^{y}\end{array}$ & $\begin{array}{c}\text { Fon1/2 no } \\
\text { match }\end{array}$ & $\begin{array}{l}\text { Fon1/2 } \\
\text { match }\end{array}$ & $\begin{array}{c}\text { Fon1/2 no } \\
\text { match }\end{array}$ & & & & \\
\hline $\mathrm{NP}$ & 4 & 3 & 1 & $\mathrm{na}^{\mathrm{z}}$ & na & 75 & 0 & 25 & 0 \\
\hline 0 & 3 & 1 & 0 & 0 & 2 & 33 & 67 & 0 & 0 \\
\hline 1 & 46 & 25 & 0 & 18 & 3 & 54 & 7 & 0 & 39 \\
\hline 2 & 120 & 42 & 44 & 34 & 0 & 35 & 0 & 37 & 28 \\
\hline Total & 173 & 71 & 45 & 52 & 5 & 41 & 3 & 26 & 30 \\
\hline
\end{tabular}

$\mathrm{v}$ Races were identified based on greenhouse pathogenicity tests with three differential cultivars. Nonpathogenic isolates had a mean disease incidence $\leq 15 \%$ (Zhou and Everts 2003).

${ }^{w}$ Number of isolates identified as the given race and tested with both primers.

x FonSIX6 primers of Niu et al. (2016). Amplification is expected with race 0 or race 1 isolates but not with nonpathogenic or race 2 isolates.

y Fon-1/Fon-2 forma specialis-specific primers of Lin et al. (2010). Amplification is expected with all pathogenic isolates, regardless of race, but not with nonpathogenic isolates.

$\mathrm{z}$ na $=$ not applicable 
not differ from incidence with the standard race 2 isolate, B05-30C1, on any of the four cultivars with only two exceptions that occurred on Carolina Strongback in only one trial each. (Petkar et al. [2019] confirmed this isolate is race 2.) In addition, incidence with the six race 2 isolates usually did not differ from incidence with the race 1 isolate on PI 296341-FR or SP-6. The readily available cultivar SP-6 may be a suitable cultivar to use in place of PI 296341-FR to identify isolates of race 3 , since incidence based on wilting or death was $\leq 25 \%$ with race 2 isolates. However, the reaction of SP-6 would have to be determined to additional isolates of race 2 and to isolates of race 3 before it could replace PI 296341-FR as a standard differential cultivar to detect race 3 .

The Fon-1/Fon-2 FON forma specialis-specific primers of Lin et al. (2010) amplified DNA from only one nonpathogenic isolate, representing $4 \%$ of the isolates that were judged nonpathogenic, i.e., had low virulence or caused no wilt symptoms in repeated tests. Likewise, the FonSIX6 primers based on an elicitor gene sequence described by Niu et al. (2016) did not amplify DNA from any of the four nonpathogenic isolates tested. Although the sample of 23 nonpathogenic isolates was small, Fon- $1 /$ Fon- 2 primers may be a useful alternative to pathogenicity tests with Sugar Baby to identify isolates of FON within a collection of $F$. oxysporum isolates. However, these primers may misidentify race 0 isolates as nonpathogenic isolates, since they did not react with two of the three race 0 isolates. Because the FonSIX6 primers amplify a fragment presumably present only in race 0 and 1 isolates, they would not be useful for identifying pathogenic isolates. The specificity of the Fon-1/Fon-2 primers of Lin et al. (2010) was better with race 1 isolates (94\%) than with race 0 isolates $(33 \%)$ or race 2 isolates $(64 \%)$ from South Carolina. Petkar et al. (2019) screened isolates of FON with the Fon-1/ Fon-2 primers prior to pathogenicity testing and genetic diversity analysis. They reported low genetic diversity of 99 isolates from Georgia and Florida. It is possible that prescreening isolates with the Fon-1/Fon-2 primers selected isolates that shared some common genetic regions and excluded isolates that would have increased the diversity of the populations. Amplification with the FonSIX6 primers of Niu et al. (2016) matched race identification for $66 \%$ of the South Carolina isolates, and specificity did not vary among the races. Neither set of primers, however, is reliable enough to replace pathogenicity testing to identify races. The primers recently designed by van Dam et al. (2018) based on candidate effector genes present in FON were not tested in this study. Their three sets of PCR primers correctly identified seven isolates of FON. Based on the reactions of the primers of Lin et al. (2010) and Niu et al. (2016) with the FON isolate collection used in this study, the primers by van Dam et al. (2018) also should be evaluated on a larger collection of FON isolates.

Variation between repeated pathogenicity tests has been reported previously (Amaradasa et al. 2018; Bruton et al. 2010; Martyn and Bruton 1989). Zhou and Everts (2003) devised mean wilt incidence across all differential cultivars inoculated to address variation between replicated tests and to facilitate designating a race for all isolates, instead of labeling isolates that yielded variable results as unknown, as Martyn and Bruton (1989) did. Races in the current study were designated using Zhou and Evert's thresholds, even though they inoculated six cultivars, whereas we inoculated three of the six cultivars they used. Mean incidence, calculated from all isolates tested by Zhou and Everts (2003) on the three cultivars we mainly used, Sugar Baby, Charleston Gray, and Allsweet, was 20, 64 , and $83 \%$, respectively, which fit into their criteria for designating races 0 ( $<33 \%$ mean incidence), 1 ( $>33 \%$ and $<66 \%$ incidence), and $2(>66 \%)$. The only conflict found in the current study was that 10 of 123 isolates of race 2 had mean wilt incidence $<66 \%$ but wilt incidence $>50 \%$ on Allsweet. We considered the traditional definition of race 2 , isolates that cause $>50 \%$ wilt incidence on cultivars resistant to race 1 , as the more compelling criterion, so these isolates were designated race 2 (Hopkins et al. 1992).

In the severely infested field in Hampton County sampled in 2008, $29 \%$ of the soil isolates were race 1 , while no race 1 isolates were recovered from symptomatic watermelon plants sampled at the same time (Keinath and Hassell 2009, 2014b). Likewise, only four isolates were identified as race 0 , race 1 , or nonpathogenic among 28 isolates obtained from field-grown plants submitted for diagnosis between 1999 and 2010 (Table 1). FON race 2 has been described as more aggressive than race 1 (Martyn and Bruton 1989), which may explain why a greater proportion of plant isolates were race 2 than race 1 . Greater aggressiveness of race 2 may also account for the high proportion of race 2 isolates recovered from diagnosis samples.

Variation in cultigen reaction to some FON isolates also was observed in this study with cultigens resistant to race 2, namely Carolina Strongback, SP-6, and PI 296341-FR. Some plants of all three cultigens, plus the few surviving plants of Allsweet, had yellow or necrotic symptoms on the cotyledons and first, or rarely, second true leaves, but no wilting or other symptoms on the rest of the plant. For all isolate-cultigen combinations, disease incidence was higher when this resistant reaction was included than when it was excluded from the ratings. Moreover, when all symptoms were rated, disease incidence on PI 296341-FR, the main source of resistance to FON, did not differ from disease incidence on Allsweet, a standard race 2 -susceptible cultivar. In addition, incidence was greater on Carolina Strongback, a rootstock cultivar with resistance to race 2, than on Allsweet for some race 2 isolates. Although Carolina Strongback is resistant to race 1 , race 1 isolate B05-07 caused higher incidence than the noninoculated control in all three trials when yellowing and necrosis of the lower leaves of Carolina Strongback were included in incidence assessments. Thus, necrosis on the lower leaves should not be included in the disease ratings assigned to PI 296341-FR and Carolina Strongback inoculated with FON. Amaradasa et al. (2018) describe complete wilting of PI 296341-FR with a race 3 isolate in four repeated experiments and $67 \%$ wilting with a race 2 isolate in one of four tests. Zhou et al. (2010) and Petkar et al. (2019) included yellowing and stunting in their assessment of symptoms caused by race 2 and race 3 isolates inoculated onto PI 296341FR, which in our opinion could cause some isolates to be misidentified as race 3 . Including yellowing and stunting in disease ratings of PI 296341-FR could be one reason the proportion of race 3 isolates (56\%) identified by Petkar et al. (2019) was higher than proportions reported in other states. In Maryland, one isolate of race 3 was found among 63 isolates $(1.6 \%)$ collected from commercial farms in 2000 (Zhou and Everts 2003; Zhou et al. 2010). In Florida, 10 of 26 FON isolates (35\%) were race 3 (Amaradasa et al. 2018), based on complete wilting.

Because most of the $F$. oxysporum $\mathrm{f}$. sp. niveum isolates from South Carolina were race 2, integrated management practices should be used until commercial cultivars with resistance to race 2 are available (Branham et al. 2017). These practices include cover cropping with hairy vetch, delaying transplanting until the soil temperature reaches $27^{\circ} \mathrm{C}$ or greater, choosing cultivars with tolerance or race 1 resistance that produce medium-sized fruit, and applications of prothioconazole at transplanting (Keinath et al. 2010, 2019; Miller et al. 2017; Sanders et al. 2012; Zhou and Everts 2007). Alternatively, grafting watermelon onto interspecific hybrid squash or bottle gourd provides a high level of protection against Fusarium wilt in naturally infested soil (Keinath and Hassell 2014a, b).

\section{Acknowledgments}

We thank C. P. Lang, A. Beacham, C. D. Conrad, A. W. Lassiter, G. V. Baccari, M. D. Rushton, and W. H. May III for technical assistance.

\section{Literature Cited}

Amaradasa, B. S., Beckham, K., Dufault, N., Sanchez, T., Ertek, T. S., Iriarte, F., Paret, M., and Ji, P. 2018. First report of Fusarium oxysporum f. sp. niveum race 3 causing wilt of watermelon in Florida, U.S.A. Plant Dis. 102:1029.

Branham, S. E., Levi, A., Farnham, M. W., and Wechter, W. P. 2017. A GBS-SNPbased linkage map and quantitative trait loci (QTL) associated with resistance to Fusarium oxysporum f. sp. niveum race 2 identified in Citrullus lanatus var. citroides. Theor. Appl. Genet. 130:319-330.

Bruton, B. D., Fish, W. W., Vivoda, E., Gabor, B., and Everts, K. L. 2010. On the reliability of Fusarium oxysporum f. sp. niveum research: Do we need standardized testing methods? Pages 222-225 in: Cucurbitaceae 2010 Proceedings, J. A. Thies, S. Kousik, and A. Levi, eds. American Society for Horticultural Science, Alexandria, VA. 
Everts, K. L., and Hochmuth, M. 2011. Field evaluation of triploid cultivars for resistance to Fusarium wilt of watermelon in Delaware, 2010. Plant Dis. Manage. Rep. 5:V175.

Hopkins, D. L., Lobinske, R. J., and Larkin, R. P. 1992. Selection for Fusarium oxysporum f. sp. niveum race 2 in monocultures of watermelon cultivars resistant to Fusarium wilt. Phytopathology 82:290-293.

Keinath, A. P., Coolong, T. W., Lanier, J. D., and Ji, P. 2019. Managing Fusarium wilt of watermelon with delayed transplanting and cultivar resistance. Plant Dis. 103:44-50.

Keinath, A. P., and DuBose, V. B. 2009. First report of Fusarium oxysporum f. sp. niveum race 2 in South Carolina watermelon fields. (Abstr.). Phytopathology 99:S63.

Keinath, A. P., and Hassell, R. L. 2009. On-farm evaluation of hairy vetch and fumigation for integrated control of Fusarium wilt on seedless watermelon, 2008. Plant Dis. Manage. Rep. 3:V035.

Keinath, A. P., and Hassell, R. L. 2014a. Control of Fusarium wilt of watermelon by grafting onto bottlegourd or interspecific hybrid squash despite colonization of rootstocks by Fusarium. Plant Dis. 98:255-266.

Keinath, A. P., and Hassell, R. L. 2014b. Suppression of Fusarium wilt caused by Fusarium oxysporum f. sp. niveum race 2 on grafted triploid watermelon. Plant Dis. 98:1326-1332.

Keinath, A. P., Hassell, R. L., and DuBose, V. B. 2006. Evaluation of mini and pollenizer watermelons for susceptibility to Fusarium wilt, powdery mildew, and gummy stem blight. Biologic. Cult. Tests 21:V002.

Keinath, A. P., Hassell, R. L., Everts, K. L., and Zhou, X.-G. 2010. Cover crops of hybrid common vetch reduce Fusarium wilt of seedless watermelon in the eastern United States. Plant Health Prog. 11.

Kemble, J. M., Meadows, I. M., Jennings, K. M., and Walgenbach, J. F., eds. Revised 2020. Southeastern U.S. Vegetable Crop Handbook. https://www.aces.edu/blog/ topics/vegetable-crops/southeastern-us-vegetable-crop-handbook

Komada, H. 1975. Development of a selective medium for quantitative isolation of Fusarium oxysporum from natural soils. Rev. Plant Prot. Res. 8:114-124.

Lin, Y.-H., Chen, K.-S., Chang, J.-Y., Wan, Y.-L., Hsu, C.-C., Huang, J.-W., and Chang, P.-F. L. 2010. Development of the molecular methods for rapid detection and differentiation of Fusarium oxysporum and $F$. oxysporum $\mathrm{f}$. sp. niveum in Taiwan. N. Biotechnol. 27:409-418.

Martyn, R. D. 2014. Fusarium wilt of watermelon: 120 years of research. Hortic. Rev. 42:349-442.
Martyn, R. D. 2017. Fusarium wilt of watermelon. Pages 38-40 in: Compendium of Cucurbit Diseases and Pests, 2nd Ed., A. P. Keinath, W. M. Wintermantel, and T. A. Zitter, eds. American Phytopathological Society Press, St. Paul, MN

Martyn, R. D., and Bruton, B. B. 1989. An initial survey of the United States for races of Fusarium oxysporum f. sp. niveum. HortScience 24:696-698.

Martyn, R. D., and McLaughlin, R. J. 1983. Effects of inoculum concentration on the apparent resistance of watermelons to Fusarium oxysporum f. sp. niveum. Plant Dis. 67:493-495.

Miller, N., Adams, M. L., and Quesada-Ocampo, L. M. 2017. Evaluation of fungicides for the management of Fusarium wilt of watermelon in Salisbury, NC, 2016. Plant Dis. Manag. Rep. 11:V135.

Niu, X., Zhao, X., Ling, K.-S., Levi, A., Sun, Y., and Fan, M. 2016. The FonSIX6 gene acts as an avirulence effector in the Fusarium oxysporum f. sp. niveum watermelon pathosystem. Sci. Rep. 6:28146.

Petkar, A., Harris-Shultz, K., Wang, H., Brewer, M. T., Sumabat, L., and Ji, P. 2019 Genetic and phenotypic diversity of Fusarium oxysporum $\mathrm{f}$. sp. niveum populations from watermelon in the southeastern United States. PLoS One 14:e0219821.

Sanders, F. H., Jr., Langston, D. B., Jr., and Flanders, T. 2012. Evaluation of fungicides and application methods for the control of Fusarium wilt of watermelon in Georgia III, 2011. Plant Dis. Manag. Rep. 6:V139.

van Dam, P., de Sain, M., ter Horst, A., van der Gragt, M., and Rep, M. 2018. Use of comparative genomics-based markers for discrimination of host specificity in Fusarium oxysporum. Appl. Environ. Microbiol. 84:e01868-17.

Wechter, W. P., Kousik, C., McMillan, M., and Levi, A. 2012. Identification of resistance to Fusarium oxysporum $\mathrm{f}$. sp. niveum race 2 in Citrullus lanatus var. citroides Plant Introductions. HortSci. 47:334-338.

Wechter, W. P., McMillan, M. M., Farnham, M. W., and Levi, A. 2016. Watermelon germplasm lines USVL246-FR2 and USVL252-FR2 tolerant to Fusarium oxysporum f. sp. niveum race 2. HortScience 51:1065-1067.

Zhou, X. G., and Everts, K. L. 2003. Races and inoculum density of Fusarium oxysporum $\mathrm{f}$. sp. niveum in commercial watermelon fields in Maryland and Delaware. Plant Dis. 87:692-698.

Zhou, X. G., and Everts, K. L. 2007. Effects of host resistance and inoculum density on the suppression of Fusarium wilt of watermelon induced by hairy vetch. Plant Dis. 91:92-96.

Zhou, X. G., Everts, K. L., and Bruton, B. D. 2010. Race 3, a new and highly virulent race of Fusarium oxysporum f. sp. niveum causing Fusarium wilt in watermelon. Plant Dis. 94:92-98. 